\title{
Time trends of overweight and obesity among schoolchildren in Kuwait over a 13-year period (2007-2019): repeated cross-sectional study
}

\author{
Abdullah Al-Taiar ${ }^{1, *}$ (D), Nawal Alqaoud², Ali H Ziyab³, Faheema Alanezi², \\ Monica Subhakaran ${ }^{2}$, Reem Sharaf Alddin ${ }^{4}$, Hueiwang Anna Jeng ${ }^{1}$ and \\ Muge Akpinar-Elci ${ }^{1}$ \\ 'School of Community \& Environmental Health, College of Health Sciences, Old Dominion University, 3136 Health \\ Sciences Building, 4608 Hampton Blvd, Norfolk, VA 23508, USA: ${ }^{2}$ Food and Nutrition Administration, Ministry of \\ Health, Kuwait City, Kuwait: ${ }^{3}$ Department of Community Medicine and Behavioral Sciences, Faculty of Medicine, \\ Kuwait University, Kuwait City, Kuwait: ${ }^{4}$ HealthCare Analytics and Delivery Science Institute, Eastern Virginia \\ Medical School, Norfolk, USA
}

Submitted 17 January 2021: Final revision received 4 June 2021: Accepted 30 July 2021: First published online 3 August 2021

\begin{abstract}
Objectives: This study aimed to examine age-specific trends in the prevalence of overweight and obesity in schoolchildren in Kuwait over a 13-year period (2007 to 2019) using the WHO, the Centers for Disease Control and Prevention (CDC) and the International Obesity Taskforce (IOTF) definitions.

Design: Using cross-sectional approach, Kuwait Nutrition Surveillance System (KNSS) objectively measured weight and height of schoolchildren over a 13-year period. Log-binomial regression models were used to examine age-specific trends of obesity and overweight over the study period.

Setting: Public primary, middle and high schools in all provinces of Kuwait.

Participants: Schoolchildren aged 5-19 years ( $n 172$ 603).

Results: According to the WHO definition, the prevalence of overweight and obesity in schoolchildren, respectively, increased from $17.73 \%$ and $21.37 \%$ in 2007 to $20 \cdot 19 \%$ and $28.39 \%$ in 2019 ( $\left.P_{\text {for trend }}<0.001\right)$. There is evidence that the obesity in females (but not males) has levelled off in the period 2014-2019 according to the three definitions of obesity, which is corroborated by a similar trend in the mean of BMI-for-age $Z$-score.

Conclusion: The prevalence of obesity and overweight in schoolchildren in Kuwait has risen over the last 13 years and trends are similar across all definitions. Obesity is no longer increasing at the same pace and there is evidence that the prevalence of obesity in females has plateaued. The current level of childhood overweight and obesity is too high and requires community-based and school-based interventions.
\end{abstract}

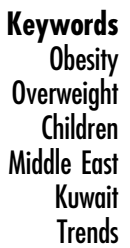

Childhood obesity remains one of the most important public health issues globally. Despite decades of efforts to control its prevalence, childhood obesity continues to cause immediate and long-term adverse health consequences $^{(1,2)}$. In the short term, children with overweight or obesity are more likely to suffer from asthma ${ }^{(3,4)}$, fatty liver disease ${ }^{(5)}$, systemic inflammation ${ }^{(6,7)}$, musculoskeletal disorders ${ }^{(8)}$, higher metabolic and cardiovascular risk $^{(9,10)}$, including high blood pressure ${ }^{(11,12)}$, and type 2 diabetes $^{(13,14)}$ in addition to several psychological issues such as depression ${ }^{(15,16)}$, anxiety ${ }^{(17)}$, low self-esteem ${ }^{(18)}$, and low academic and cognitive performance ${ }^{(18,19)}$ Long-term complications of childhood obesity may include increased risk of developing $\operatorname{CVD}^{(20,21)}$, type 2 diabetes $^{(22-24)}$, some cancers ${ }^{(25,26)}$, physical disability ${ }^{(27,28)}$ and pre-mature death ${ }^{(29-31)}$. Furthermore, children with overweight or obesity are more likely to have overweight or obesity in adulthood compared to their normal-weight peers $^{(32-34)}$. Against this background, obesity should be prevented at the earliest possible stage of life to mitigate the risk of many diseases in childhood and adulthood, particularly with the low efficacy of the available treatments ${ }^{(35,36)}$. 
As per the comprehensive plan for Maternal, Infant and Young Child Nutrition, the WHO aims to have zero increase in childhood overweight by $2025^{(37)}$, which is consistent with the other target for obesity and type 2 diabetes between 2010 and 2025 in the "WHO Global Action Plan for the Prevention and Control of Non-communicable Diseases 2013-2020 $0^{(38,39)}$. Assessing the progress on these targets requires data on the trends of obesity and overweight, which is critical for policy development ${ }^{(40)}$. Although the data on recent trends of childhood obesity are available from Europe, North America, Australia and China, there is a lack of data on secular trends of childhood obesity from the rest of the world, particularly in the Middle East. When data do exist from the Middle East region, it is usually based on literature reviews of individual methodologically heterogenous studies ${ }^{(41-46)}$ providing contradictory findings. The only exception is a new report from Iran where the authors examined the trends of waist-to-height ratio in children between 2003 and 2015, demonstrating an increasing trend of the prevalence of abdominal obesity in Iranian children ${ }^{(47)}$.

Prevalence of obesity has increased substantially in children and adolescents around the world ${ }^{(2)}$ but recently, there has been some flattening of trends or probably a reduction in the prevalence of childhood obesity, particularly among children with high socio-economic status in high-income countries ${ }^{(2,48,49)}$ such as the USA $^{(50,51)}$, Canada ${ }^{(52)}$, Spain ${ }^{(53)}$, Australia ${ }^{(54)}$, Germany ${ }^{(55)}$, France ${ }^{(56,57)}$, the Netherlands ${ }^{(58)}$, Switzerland ${ }^{(59)}$ and Sweden ${ }^{(60)}$. However, there is paucity of data on the recent trends of childhood obesity in Middle Eastern settings, particularly in the oil-rich Arab states in the Gulf region, where the socioeconomic status has improved materially during the last few decades with strong shift towards an obesogenic environment, including high energy density foods coupled with low physical activity $^{(61)}$. In these settings, several individual studies have estimated the point prevalence of childhood obesity in various age groups at different points in time and there is a general consensus that the prevalence of childhood obesity is similar to or higher than that in high-income countries in North America or Europe. In Kuwait, for example, it has been reported that $21.6 \%$ and $30.5 \%$ of schoolchildren have overweight or obesity, respectively ${ }^{(62)}$. In a recent study, $42 \%$ of female university students had obesity based on their BMI and $62 \%$ had excessive fatness as measured by bioelectric impedance analysis $^{(63)}$. However, it is not clear whether the weight status of children and adolescents is stabilising, particularly in school aged children 5-19 years, among which the obesity had increased globally more rapidly between 1975 and 2016 compared to younger pre-school children ${ }^{(35)}$.

For over a decade, Kuwait Nutrition Surveillance System (KNSS) objectively measured the weight and height of thousands of schoolchildren (5-19 years) annually using standardised protocol. This provides a unique opportunity to examine recent trends of obesity in schoolchildren in Kuwait over several years and to compare them to that reported from other high-income countries. This study used individual data records collected over a 13-year period (2007-2019) by KNSS to, for the first time, examine age-specific trends in the prevalence of childhood obesity in schoolchildren in Kuwait based on BMI using various definitions of childhood obesity including the $\mathrm{WHO}^{(64)}$, the Centers for Disease Control and Prevention $(\mathrm{CDC})^{(65)}$, and the International Obesity Taskforce (IOTF) ${ }^{(66,67)}$.

\section{Methods}

\section{Study site and KNSS}

Kuwait is a small country with a population of 4.7 million with approximately $25 \%$ of its population under the age of 19 years. School enrolment is extremely high for both males and females ${ }^{(68)}$, with approximately $25 \%$ of students enrolled in private schools. Unlike private schools, public schools are single-sex schools at all levels with total number of students approximately 476000 . There is no clearly recognised race or ethnic classification of the population of Kuwait.

KNSS is a public health activity funded by the government to collect data on the nutritional status of the population by trained data collectors who are employed on a longterm basis for this purpose. The aim of KNSS is to provide nationwide information on the trends of nutritional status on all age groups over time. KNSS is mainly a repeated cross-sectional study that collects data using separate data collection forms on children $\leq 24$ months, children> 2 years to $<5$ years, schoolchildren ( $5-19$ years) and adults. In 2014, KNSS was reviewed, and all data collection forms were updated except for schoolchildren (More details on KNSS have been published before $\left.{ }^{(69)}\right)$. In this age group, only anthropometric measures are conducted with no other data are collected on socio-economic status, dietary habits or physical activity. Such data are collected by a different department using Global School-Based Student Health Survey (GSHS) questionnaire ${ }^{(70)}$. Unlike KNSS, weight and height of schoolchildren in GSHS are self-reported. KNSS includes children aged 5-19 years from public primary, middle and high schools in all governorates (provinces) of Kuwait. In each governorate, at least one school for males and one school for females is randomly selected from each primary, middle and high schools making sure the same school is not selected in two consecutive years. For the current analysis, KNSS data from 2007 to 2019 were used.

\section{Data collection and measurement of weight and height}

Body weight was measured to the nearest $0 \cdot 1 \mathrm{~kg}$ using calibrated digital scales $\left(\mathrm{SECA}^{\circledR}\right)$ without shoes or heavy clothing. Height was measured to the nearest $0 \cdot 1 \mathrm{~cm}$ using a stadiometer $\left(\right.$ SECA $\left.^{\circledR}\right)$ with full extended knees and shoes off. Sex and date of birth were extracted from the school 
records. Data on socio-economic factors, diet or physical activity were not collected at any point in time.

\section{Statistical methods}

BMI was calculated by dividing the weight in kilograms by squared height in metres. Age was calculated in days by subtracting the date of birth from the date of data collection and then converted into years. First, BMI-for-age $Z$-scores were calculated according to the WHO growth reference curves $^{(64)}$, and then overweight was defined as $>1$ SD but $\leq 2$ SD of the WHO growth reference median, while obesity was defined as $>2 \mathrm{SD}$ of the WHO growth reference median. Second, BMI-for-age $Z$-scores were calculated according to the CDC growth reference curves ${ }^{(65)}$, which were turned into percentiles, and the overweight and obesity were defined as $\geq 85$ th percentiles and $\geq 95$ th percentiles, respectively. Third, the calculated BMI was categorised according to the IOTF definition ${ }^{(66,67)}$. Unlike WHO definition that uses arbitrarily chosen cut-off points, IOTF definition uses smooth sex-specific BMI curves, constructed to match the values of $25 \mathrm{~kg} / \mathrm{m}^{2}$ (to define overweight) and $30 \mathrm{~kg} / \mathrm{m}^{2}$ (to define obesity) at the age of 18 years. The three definitions of overweight and obesity were used to facilitate international comparisons and to help create a pool of studies that allows developing algorithm that converts the prevalence of overweight and obesity from one definition to another. In this article, the term 'overweight' does not include obesity unless stated otherwise.

The age-specific prevalence (95\% CI) of obesity and overweight (including obesity) was plotted using the three definitions of obesity in children over the study period while stratifying by sex. Moreover, the overall and the age-specific mean BMI-for-age of $Z$-scores calculated from the WHO reference curves and their $95 \%$ CI were plotted over years of study while stratifying by sex. With the large number of observations, the regular scatterplot which plots every data point became too crowded to interpret visually; therefore, binned scatterplots were used controlling for age and stratifying by sex generated by STATA command 'binscatter' to graphically present the change in the mean BMI-for-age $Z$-score over the study period.

The analysis started by calculating the odds of obesity and overweight (including obesity) over the study period while stratifying by sex and adjusting for age. Three separate analyses according to the three definitions of overweight and obesity were conducted to investigate the trends in obesity and overweight (including obesity) over the study period using log-binomial regression models. In this analysis, the prevalence ratio for obesity was estimated while adjusting for age and stratifying by sex fitting the main independent variable (year of measurement 2007 to 2019) as a continuous variable. In this analysis, a quadratic time (year of study) term was fitted to assess non-linearity, which was found to be significant. STATA $14.2^{(71)}$ was used to fit models with both linear and quadratic time terms with obesity (yes $=1$ and no $=0$ ) as well as overweight (including obesity) as the binary dependent variables. In these models, the standard error was calculated while taking the clustering effect into account using the variance-covariance matrix (vce) option in STATA. Guided by this analysis, aggregated data were used in NCI's Joinpoint software ${ }^{(72)}$ to identify the location of joinpoints for each age group and sex as per the guidelines $^{(73)}$. In this analysis, the proportions were calculated within the joinpoint software with all other settings according to the Joinpoint software default. The joinpoints were also investigated using hockey stick regression method using STATA command 'loghockey'.

\section{Results}

Of all data records, 392 records were excluded because BMI-for-age $Z$-scores were biologically implausible (BMI-for-age $Z$-score $<-5$ or BMI-for-age $Z$-scores $>+5$ ). The total number of schoolchildren included in this analysis was 172603 of which 85764 (49.69\%) were females. Table 1 shows the distribution of the study participants by age and year of study. The crude prevalence of overweight and obesity over the entire 13-year study period was $19 \cdot 86 \%$ (95\% CI 19.15, 20.61) and $25.63 \%$ (95\% CI $23 \cdot 20,28 \cdot 23)$, respectively, according to the WHO definition, $16.06 \%(95 \% \mathrm{CI} 15 \cdot 35,16.81)$ and $25.01 \%(95 \% \mathrm{CI}$ $22 \cdot 62,27 \cdot 56)$, respectively, according to the CDC definition, and $20.57 \%$ (95\% CI 19.59, 21.59) and $19.59 \%$ (95\% CI $17 \cdot 53,21 \cdot 83)$, respectively, according to the IOTF definition.

\section{Trends in the prevalence of overweight and obesity in schoolchildren}

According to the WHO definition, the prevalence of overweight and obesity, respectively, increased from $17.73 \%$ and $21.37 \%$ in 2007 to $20.19 \%$ and $28.39 \%$ in 2019 ( $P_{\text {for trends }}$ in odds of each overweight and obesity <0.001). This remained evident while stratifying by sex and adjusting for age. Table 2 shows the prevalence of overweight and obesity by sex and year of data collection during the study period. Supplemental Tables S1 and S2 show the prevalence of overweight and obesity by sex and year according to the CDC definition and the IOTF definition, respectively.

Figure 1 shows the prevalence of obesity and overweight (including obesity) and their $95 \%$ CI over the 13-year period according to the WHO, the CDC and the IOTF definitions among males, females and both sexes. The age-specific prevalence of obesity and overweight (including obesity) and their $95 \%$ CI over the 13-year study period stratified by sex are shown in the supplementary material according to the WHO definition (see online supplemental Fig. S1(a) and S1(b)), the CDC definition (see online supplemental Fig. S2(a) and S2(b)) and the IOTF definition (see online supplemental Fig. S3(a) and 
S3(b)). All figures clearly indicate that the prevalence of obesity generally increased over the 13-year study period and the trends have slowed down in later years.

The analysis of trends in the prevalence of obesity and overweight (including obesity) in schoolchildren (5-19 years) between 2007 and 2019 after adjusting for age and stratification by sex is shown in Table 3. This analysis confirmed that the prevalence of obesity and overweight (including obesity) increased over the study period according to the $\mathrm{WHO}$, the $\mathrm{CDC}$ and the IOTF definitions. To investigate whether the prevalence of obesity and overweight (including obesity) started to level off (nonlinearity), we fitted a quadratic term of the explanatory variable (years of the study) in addition to the linear term. This was statistically significant in the model indicating that the trend is non-linear. Guided by this and the Fig. 1, we conducted a joinpoint analysis to search for one joinpoint around which the increase of obesity has abated. We found one joinpoint around 2013 for both sexes, which was confirmed using hockey stick regression analysis. To investigate this further, we omitted data from 2013 and another joinpoint emerged around 2010. Then, we examined the trends before and after 2013 while stratifying the analysis by sex and adjusting for age (data not shown). This analysis confirmed that in males, there was a significant upward trend in the prevalence of obesity and overweight (including obesity) before and after 2013. In females, significant upward trend in the prevalence of overweight (including obesity) before and after 2013 was found, but no significant trend was found after 2013 in the prevalence of obesity, which suggest that the prevalence of obesity may have stabilised in females. These findings remain the same when the analysis was repeated using the CDC and the IOTF definitions.

\section{Trends in the BMI-for-age Z-score in schoolchildren}

The mean BMI-for-age $Z$-scores and their 95\% CI calculated from the WHO reference curves over the 13-year study period in males and females and both sexes are shown in Fig. 2. Supplemental Fig. S4(a) and S4(b) show the age-specific mean BMI-for-age $Z$-scores over the study period in males and females, respectively. Figure 3 shows the bin scatter of BMI-for-age $Z$-score over the study period after controlling for age while fitting regression line with quadratic time term. All figures showed an increase in the mean BMI-for-age $Z$-score during the 13-year study period in a pattern consistent with the increase in the prevalence of obesity and overweight demonstrated above.

\section{Discussion}

For the first time, using individual data records of thousands of children, this study examined the age-specific trends in 
Table 2 Prevalence of overweight and obesity in schoolchildren (5-19 years) in Kuwait between 2007 and 2019 according to the WHO definition of obesity in children

\begin{tabular}{|c|c|c|c|c|c|c|}
\hline \multirow[b]{2}{*}{ Year } & \multicolumn{2}{|c|}{ Male } & \multicolumn{2}{|c|}{ Female } & \multicolumn{2}{|c|}{ Total } \\
\hline & Overweight (\%) & Obesity (\%) & Overweight (\%) & Obesity (\%) & Overweight (\%) & Obesity (\%) \\
\hline 2007 & $16 \cdot 43$ & $23 \cdot 16$ & $19 \cdot 02$ & $19 \cdot 59$ & $17 \cdot 73$ & $21 \cdot 37$ \\
\hline 2008 & $16 \cdot 30$ & 23.06 & $20 \cdot 48$ & 18.35 & $18 \cdot 36$ & $20 \cdot 74$ \\
\hline 2009 & 17.96 & 23.85 & 21.04 & 21.67 & 19.54 & 22.74 \\
\hline 2010 & 17.84 & 26.96 & 22.00 & 21.81 & 19.98 & 24.31 \\
\hline 2011 & 17.63 & $28 \cdot 19$ & $21 \cdot 72$ & $22 \cdot 82$ & $19 \cdot 72$ & 25.45 \\
\hline 2012 & 17.04 & $28 \cdot 28$ & $20 \cdot 58$ & 22.07 & $18 \cdot 82$ & $25 \cdot 15$ \\
\hline 2013 & $19 \cdot 17$ & $32 \cdot 34$ & 22.90 & $25 \cdot 20$ & $20 \cdot 86$ & $29 \cdot 10$ \\
\hline 2014 & $17 \cdot 36$ & 28.72 & 22.09 & 23.55 & $19 \cdot 68$ & $26 \cdot 18$ \\
\hline 2015 & 17.96 & $29 \cdot 73$ & 21.66 & 22.99 & 19.86 & $26 \cdot 28$ \\
\hline 2016 & 18.53 & $29 \cdot 32$ & $21 \cdot 62$ & $22 \cdot 64$ & $20 \cdot 06$ & 26.01 \\
\hline 2017 & $18 \cdot 41$ & $28 \cdot 11$ & 22.97 & 23.03 & $20 \cdot 69$ & $25 \cdot 57$ \\
\hline 2018 & 18.40 & 31.45 & 24.25 & 23.84 & 21.47 & 27.46 \\
\hline 2019 & $18 \cdot 70$ & 33.06 & $21 \cdot 72$ & 23.56 & $20 \cdot 19$ & 28.39 \\
\hline Overall & 17.95 & $28 \cdot 61$ & 21.81 & $22 \cdot 62$ & 19.87 & $25 \cdot 63$ \\
\hline$P$-value & \multicolumn{2}{|c|}{$P<0.001$} & \multicolumn{2}{|c|}{$P<0.001$} & \multicolumn{2}{|c|}{$P<0.001$} \\
\hline
\end{tabular}

Obesity was defined as $>2$ SD while overweight was defined $>1$ SD but $\leq 2$ SD of the WHO growth reference median.

$P$-value, testing for trends during the study period.
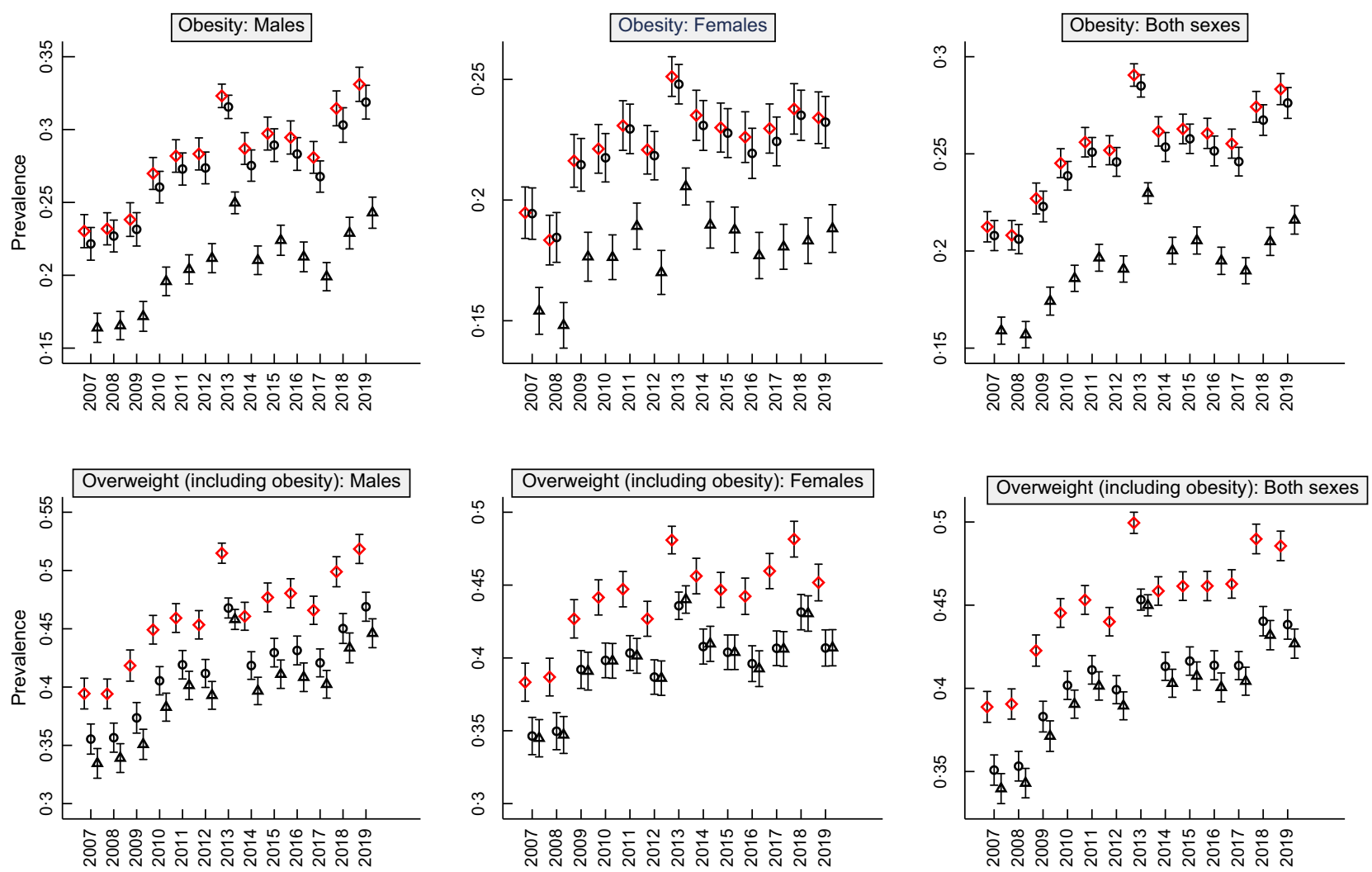

$\diamond$ WHO definition $\quad \circ \quad$ CDC definition $\quad \Delta$ ITOF definition

Fig. 1 (colour online) Prevalence of overweight (including obesity) and obesity and their $95 \% \mathrm{Cl}$ over 13-year period according to the $\mathrm{WHO}$, the CDC and the IOTF definitions among males, females and both sexes. CDC, the Centers for Disease Control and Prevention; IOTF, the International Obesity Taskforce

the prevalence of overweight and obesity in male and female schoolchildren aged 5-19 years in Kuwait, an oilrich country in the Middle East that represents a group of countries in that region where an obesogenic environment has expanded for years ${ }^{(61)}$. Overall, the prevalence of overweight and obesity in schoolchildren (5-19 years) has risen over the past 13 years in Kuwait and that it has recently started to level off in females. These findings are extremely 
Table 3 Trends in the prevalence of overweight and obesity in schoolchildren (5-19 years) in Kuwait between 2007 and 2019 using log-binomial regression

\begin{tabular}{|c|c|c|c|c|c|c|c|c|c|}
\hline & $\begin{array}{c}\text { WHO } \\
\text { definition } \\
\text { PR }\end{array}$ & $95 \% \mathrm{Cl}$ & $P$-value & $\begin{array}{c}\text { CDC } \\
\text { definition } \\
\text { PR }\end{array}$ & $95 \% \mathrm{Cl}$ & $P$-value & $\begin{array}{c}\text { IOTF } \\
\text { definition } \\
\text { PR }\end{array}$ & $95 \% \mathrm{Cl}$ & $P$-value \\
\hline \multicolumn{10}{|l|}{ Overweight (including obesity)† } \\
\hline Males Year (2007 to 2019) & 1.04 & $1.02,1.05^{\star \star}$ & $<0.001$ & 1.04 & $1.02,1.05$ & $<0.001$ & 1.05 & $1 \cdot 01,1 \cdot 10^{*}$ & 0.007 \\
\hline Females Year (2007 to 2019$)$ & 1.03 & $1.02,1.05^{\star \star}$ & $<0.001$ & 1.03 & $1.01,1.05^{\star}$ & 0.001 & 1.05 & $1 \cdot 01,1 \cdot 10^{*}$ & \\
\hline \multicolumn{10}{|l|}{ Only obesity† } \\
\hline Year (2007 to 2019) & 1.05 & $1.02,1.08^{\star}$ & $<0.001$ & 1.05 & $1.02,1.07$ & $<0.001$ & 1.03 & $1.02,1.05^{\star}$ & $<0.001$ \\
\hline Females Year (2007 to 2019) & 1.05 & $1.01,1.09^{\star}$ & 0.012 & 1.05 & $1.01,1.09^{\star}$ & 0.011 & 1.03 & $1.01,1.05^{\star}$ & 0.003 \\
\hline
\end{tabular}

CDC: Centers for Disease Control and Prevention; IOTF: International Obesity Taskforce; PR: prevalence ratio; $95 \% \mathrm{Cl}$.

After taking clustering into account, quadratic time term was significant at $5 \%$ level of significance indicated by '**' or at $10 \%$ level of significance indicated by '**

†ln all models, we adjusted for age as a continuous variable.
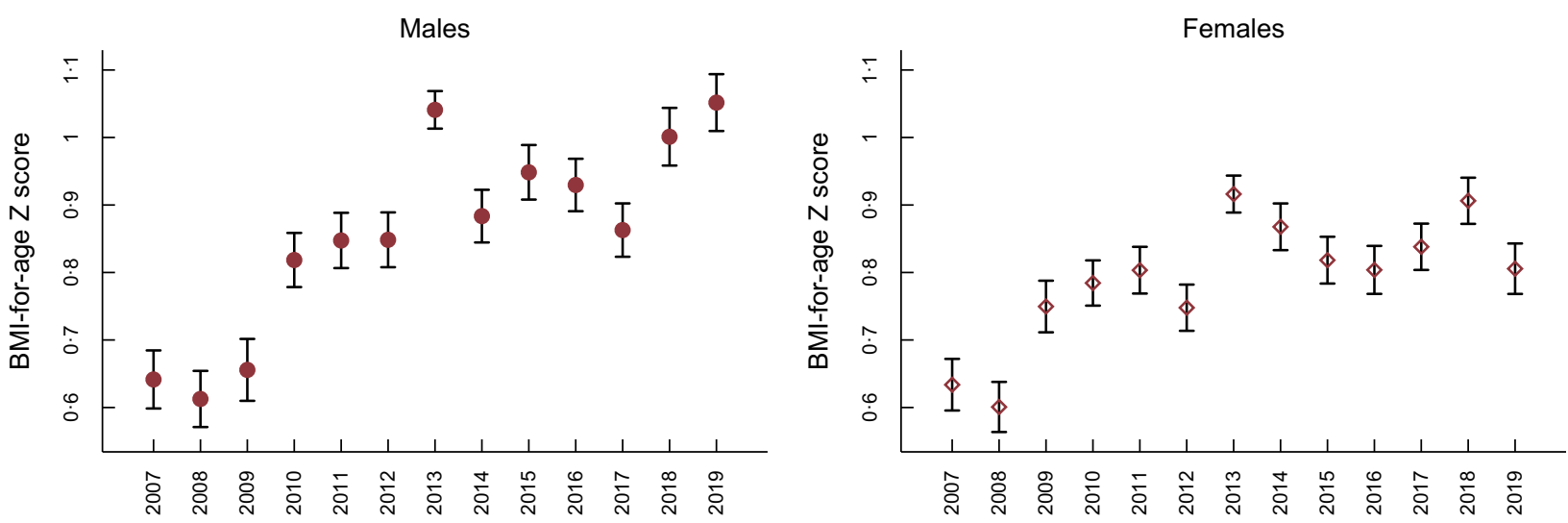

Both sexes

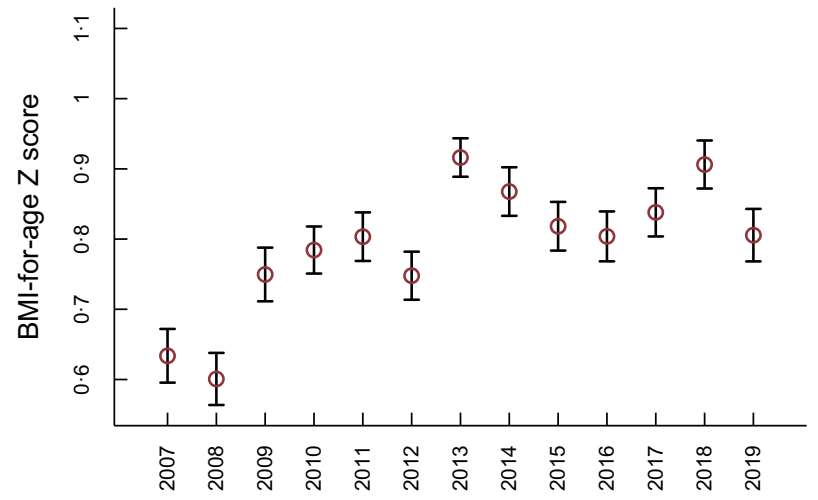

Fig. 2 (colour online) Mean BMI-for-age Z-scores and their $95 \% \mathrm{Cl}$ calculated from the WHO reference curves over the 13-year study period in males and females and both sexes

important because there is little data on trends of childhood obesity from Middle Eastern settings except for few literature reviews of methodologically heterogenous studies that show contradictory findings ${ }^{(41-46)}$.

There was an increase in the prevalence of childhood obesity as well as overweight (including obesity) in Kuwait according to the three definitions of childhood obesity and overweight (WHO, CDC and IOTF). At the end of the study period in 2019 , the prevalence of obesity and overweight was $20.19 \%$ and $28.39 \%$, respectively, which is similar to that in $\operatorname{Italy}{ }^{(74)}$ but higher than that reported in several high-income countries ${ }^{(59,75)}$. In fact, a recent literature review of obesity in schoolchildren at a global level has identified Kuwait as having the highest prevalence of obesity and overweight in the Middle East and North Africa (MENA) region ${ }^{(35)}$. Over the last few decades, high oil revenue has contributed to substantial improvement in the standard of living for citizens that includes highly subsidised foods. Exclusive breast-feeding during the first 6 months of birth, which has been linked to lower obesity rates during adolescence ${ }^{(76)}$, is also low; and the government provides highly subsidised 


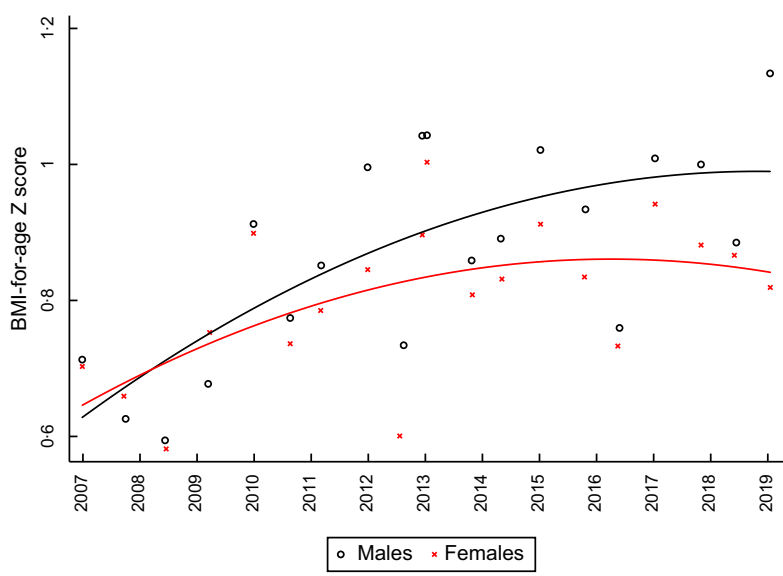

Fig. 3 (colour online) Bin scatter of BMI-for-age Z-score over 13-year period after controlling for age fitting regression line with quadratic time term

formula milk ${ }^{(69)}$. GSHS data suggest that more than $62 \%$ of schoolchildren spend 3 or more $\mathrm{h} / \mathrm{d}$ sitting and watching television, playing computer games, or talking with friends. Also, less than $17 \%$ of schoolchildren were physically active at least $60 \mathrm{~min} / \mathrm{d}$; and more than $52 \%$ of students consumed carbonated soft drinks 1 or more times/d during the $30 \mathrm{~d}$ before the survey ${ }^{(70)}$.

In this study, a significant upward trend in the prevalence of obesity and overweight (including obesity) was found in schoolchildren from 2007 until 2014 in both sexes. At a global level, it has been reported that the obesity in schoolchildren has increased over the last few decades in a higher rate compared to that in pre-school children ${ }^{(35)}$. It has been suggested that as children get older, that is, from pre-school age to adolescence, they gain independence and thus are capable of making their own lifestyle choices such as choosing which foods they consume and the level of physical activity that they participate in, which may explain the rapid increase in the prevalence of obesity in this particular age group ${ }^{(35,77,78)}$. Throughout the study period, girls had a lower prevalence of obesity and higher prevalence of overweight than boys, a pattern that has been reported in Iranian children ${ }^{(41)}$. Several studies have reported higher prevalence of obesity in boys compared to girls in different settings ${ }^{(53,79)}$ including Kuwait ${ }^{(62)}$. Currently, there are calls to investigate the rapid increase of obesity in boys and whether they are more susceptible to obesogenic pressures ${ }^{(35)}$.

Although the prevalence of childhood obesity has increased in the last 13 years, the data suggest that the prevalence may have levelled off in females since 2013 as there was no significant trend in the prevalence of obesity in the period 2014-2019 after adjusting for age. When the analysis was stratified by sex and age, there was no increase in obesity among girls in any age group except a slight increase in those older than 17 years in the period 2014-2019. The prevalence peaked in year 2013 with no clear explanation. Therefore, the analysis was repeated while omitting the data from 2013, which produced similar results. Although several recent reports indicate that the trend in childhood obesity may have slowed down or even decreased in high-income countries $^{(48-53,58-60,75,80)}$, this issue remains highly controversial and poorly understood. In England, based on data from primary care electronic records, it was reported that the annual increase in the prevalence of obesity stabilised in younger ( $2-10$ years) children but not older (11-15 years) children among which obesity continues to increase with no difference between males and females ${ }^{(81)}$. In the same setting, an earlier study showed that the prevalence of obesity among girls declined between 2005 and 2007 while it remained stable or increased in boys ${ }^{(82)}$. Surprisingly, in the same setting, upward trends have been reported for both males and females since 2012 $2^{(75)}$. In Swedish schoolchildren, it was demonstrated that the obesity declined in females not males ${ }^{(83)}$. Also, although within a short period of time frame (2007 to 2010), data from the WHO European Childhood Obesity Surveillance Initiative showed upward trend in some countries and downward trends in other countries in Europe over the same period of time ${ }^{(84)}$. Finally, in children aged 3 to 17 years, a relatively stable rates of obesity were reported in France up to 2012, while since 2011 the rates of obesity have increased in boys in the USA ${ }^{(75)}$.

The data suggest that obesity in female schoolchildren may be slowing down in recent years according to the WHO, the CDC and the IOTF definitions, which was supported by similar trends in the mean BMI-for-age $Z$-score that showed significant increase over time but started to level off around 2013-2014. This is consistent with several reports from Europe ${ }^{(82,83)}$ and a recent global review of trends in childhood obesity, where a higher increase in obesity was observed in boys in comparison to girls between 1975 and 2016 $6^{(35)}$. Our findings highlight the importance of sex differences, which should be considered in the intervention programmes designed to combat obesity in children and adolescents ${ }^{(85,86)}$. Several plausible reasons for the recent plateau in the trend of childhood obesity have been proposed including the notion that the rates have reached a point of saturation ${ }^{(80)}$. The other possible reason is the cumulative impact of public health campaigns, which may have resulted in body weight awareness and hence stabilisation of the prevalence of obesity in female schoolchildren. However, it is not clear whether this stabilisation will be a critical juncture or just a temporary trend. Knowing this may require further monitoring of future trends while including data from different sources. It is noteworthy that upwards trends in childhood obesity have been reported in countries where childhood obesity had plateaued or even declined ${ }^{(75,84)}$.

In this study, three definitions of obesity and overweight among children were used to facilitate international comparisons with our data. The WHO definition provided the highest estimate of the prevalence, while the IOTF 
definition showed the lowest estimate of the prevalence of both overweight and obesity among schoolchildren in Kuwait. This is similar to that reported earlier from the region $^{(87)}$ and Italy ${ }^{(88)}$. The results of this study also suggest that the WHO, the CDC and the IOTF definitions can all be used to ascertain the trends of overweight and obesity in schoolchildren over time in the region, but the interpretation of the magnitude of the prevalence should take into account the definition used. Using national recently collected BMI-for-age reference data is not recommended to define overweight and obesity in children as it may underestimate childhood obesity providing false assurance that may undermine the need for public health interventions ${ }^{(89)}$.

The study has several strengths including the large sample size which allowed us to investigate age-specific trends in overweight and obesity after stratification by sex. Also, the data were based on objectively measured weight and height rather than reported weight and height by children or their parents. It has been demonstrated that adolescents and adults underreport weight and overreport height, which leads to lower BMI values ${ }^{(90,91)}$. Moreover, weight and height measurements were conducted by a trained team who are employed on a long-term basis for this purpose hence allowing for consistency of data collection. However, the study has some limitations including the lack of data on socio-economic status. Given the objectives of this study (i.e. examining the trends of obesity over time), this should cause little concern because we are not looking for specific factors associated with the trends in childhood obesity. Nevertheless, the lack of data on socioeconomic status may conceal different patterns of trend in childhood obesity between those with high and low socioeconomic status. Private schools are excluded from KNSS which may hinder the generalisability of the findings. Additionally, although BMI is a valid, convenient and reliable method of assessing weight status (whereby weight becomes a surrogate for fatness), the ideal definition of obesity is based on the percentage of body fat but this is impracticable for epidemiological studies as it requires body composition analysis using reliable methods such as dual-energy X-ray absorptiometry (DEXA) ${ }^{(92)}$.

In conclusion, the prevalence of obesity and overweight among schoolchildren in Kuwait has risen over the last 13 years and trends are similar across various definitions. The findings of this report indicate that obesity is no longer increasing at the same pace and there is some evidence that the prevalence of obesity in female schoolchildren has plateaued. These findings should not be interpreted as grounds for optimism as they may reflect a transient trend and nevertheless, the current prevalence is extremely high in both sexes. With this current level of childhood obesity, the country needs to go beyond increasing knowledge and awareness of obesity, hence intensifies community-based interventions as well as plans, tests and implements school-based interventions to reduce the prevalence of obesity in schoolchildren.

\section{Acknowledgements}

Acknowledgements: The authors would like to thank Dr Mona Alsumaie and the data collectors at KNSS for hardwork and dedication. Financial support: KNSS is funded by the Kuwaiti government. This research received no specific grant from any funding agency, commercial or not-for-profit sectors. Conflict of interest: There are no conflicts of interest. Authorship: A.A.-T. analysed the data and drafted the manuscript. N.A.-Q. supervised data collection, contributed to data interpretation and revised the manuscript with significant intellectual input. A.H.Z. contributed to data interpretation and revised the manuscript with significant intellectual input. F.A. supervised data collection and data entry, contributed to data management and revised the manuscript with significant intellectual input. M.S. supervised data collection and data entry, contributed to data management and revised the manuscript with significant intellectual input. R.S.A. contributed to data management and data analysis in addition to drafting the article. H.A.J. contributed to data interpretation and revised the manuscript with significant intellectual input. M.A.-E. contributed to data interpretation and revised the manuscript with significant intellectual input. Ethics of buman subject participation: This study was conducted according to the guidelines laid down in the Declaration of Helsinki. The study was a secondary data analysis of completely anonymous data collected by Kuwait Nutritional Surveillance System (KNSS). All procedures of KNSS were approved by the Ethics Committee at the Ministry of Health in Kuwait (No. 98). Because KNSS is a public health activity, measuring weight and height of schoolchildren does not require parental informed consent according to the research regulations in Kuwait.

\section{Supplementary material}

For supplementary material accompanying this paper visit https://doi.org/10.1017/S1368980021003177

\section{References}

1. Lobstein T, Jackson-Leach R, Moodie ML et al. (2015) Child and adolescent obesity: part of a bigger picture. Lancet $\mathbf{3 8 5}$, 2510-2520.

2. Ng M, Fleming T, Robinson M et al. (2014) Global, regional, and national prevalence of overweight and obesity in children and adults during 1980-2013: a systematic analysis for the Global Burden of Disease Study 2013. Lancet 384, 766-781.

3. Farah CS \& Salome CM (2012) Asthma and obesity: a known association but unknown mechanism. Respirology 17, 412-421.

4. Rhee H, Love T, Groth SW et al. (2020) Associations between overweight and obesity and asthma outcomes in urban adolescents. J Asthma 57(10), 1053-1062. 
5. Shaunak M, Byrne CD, Davis N et al. (2021) Non-alcoholic fatty liver disease and childhood obesity. Arch Dis Child 106, 3-8.

6. Selvaraju V, Ayine P, Fadamiro M et al. (2019) Urinary biomarkers of inflammation and oxidative stress are elevated in obese children and correlate with a marker of endothelial dysfunction. Oxid Med Cell Longev 2019, 9604740.

7. Oliveira-Santos J, Santos R, Moreira C et al. (2019) Associations between anthropometric indicators in early life and low-grade inflammation, insulin resistance and lipid profile in adolescence. Nutr Metab Cardiovasc Dis 29, 783-792.

8. Faienza MF, D'Amato G, Chiarito M et al. (2019) Mechanisms involved in childhood obesity-related bone fragility. Front Endocrinol 10, 269.

9. Ayer J, Charakida M, Deanfield JE et al. (2015) Lifetime risk: childhood obesity and cardiovascular risk. Eur Heart J 36, 1371-1376.

10. Kelishadi R, Mirmoghtadaee P, Najafi H et al. (2015) Systematic review on the association of abdominal obesity in children and adolescents with cardio-metabolic risk factors. J Res Med Sci 20, 294-307.

11. Ding W, Cheung WW \& Mak RH (2015) Impact of obesity on kidney function and blood pressure in children. World $J$ Nephrol 4, 223-229.

12. Cai L, Wu Y, Wilson RF et al. (2014) Effect of childhood obesity prevention programs on blood pressure: a systematic review and meta-analysis. Circulation 129, 1832-1839.

13. Valaiyapathi B, Gower B \& Ashraf AP (2020) Pathophysiology of type 2 diabetes in children and adolescents. Curr Diabetes Rev 16, 220-229.

14. Spurr S, Bally J, Hill P et al. (2020) Exploring the prevalence of undiagnosed prediabetes, type 2 diabetes mellitus, and risk factors in adolescents: a systematic review. I Pediatr Nurs 50, 94-104.

15. Quek YH, Tam WWS, Zhang MWB et al. (2017) Exploring the association between childhood and adolescent obesity and depression: a meta-analysis. Obes Rev 18, 742-754.

16. Rao WW, Zong QQ, Zhang JW et al. (2020) Obesity increases the risk of depression in children and adolescents: results from a systematic review and meta-analysis. J Affect Disord 267, 78-85.

17. Wang S, Sun Q, Zhai L et al. (2019) The prevalence of depression and anxiety symptoms among overweight/obese and non-overweight/non-obese children/adolescents in China: a systematic review and meta-analysis. Int J Environ Res Public Health 16, 340.

18. Puhl RM \& Latner JD (2007) Stigma, obesity, and the health of the nation's children. Psychol Bull 133, 557-580.

19. Yang Y, Shields GS, Guo C et al. (2018) Executive function performance in obesity and overweight individuals: a meta-analysis and review. Neurosci Biobehav Rev 84, 225-244.

20. Weihrauch-Blüher S, Schwarz P \& Klusmann JH (2019) Childhood obesity: increased risk for cardiometabolic disease and cancer in adulthood. Metabolism 92, 147-152.

21. Umer A, Kelley GA, Cottrell LE et al. (2017) Childhood obesity and adult cardiovascular disease risk factors: a systematic review with meta-analysis. BMC Public Health 17, 683 .

22. Ohlsson C, Bygdell M, Nethander M et al. (2019) BMI change during puberty is an important determinant of adult type 2 diabetes risk in men. J Clin Endocrinol Metab 104, 1823-1832.

23. Kim JY, Bacha F, Tfayli H et al. (2019) Adipose tissue insulin resistance in youth on the spectrum from normal weight to obese and from normal glucose tolerance to impaired glucose tolerance to type 2 diabetes. Diabetes Care 42, 265-272.

24. Fang X, Zuo J, Zhou J et al. (2019) Childhood obesity leads to adult type 2 diabetes and coronary artery diseases: a 2-sample Mendelian randomization study. Medicine $\mathbf{9 8}$, e16825.

25. Zohar L, Rottenberg Y, Twig G et al. (2019) Adolescent overweight and obesity and the risk for pancreatic cancer among men and women: a nationwide study of 179 million Israeli adolescents. Cancer 125, 118-126.

26. Hidayat K, Du X \& Shi BM (2018) Body fatness at a young age and risks of eight types of cancer: systematic review and meta-analysis of observational studies. Obes Rev 19, 1385-1394.

27. Lee H, Pantazis A, Cheng P et al. (2016) The association between adolescent obesity and disability incidence in young adulthood. $J$ Adolesc Health 59, 472-478.

28. Henriksson P, Henriksson H, Tynelius P et al. (2019) Fitness and body mass index during adolescence and disability later in life: a cohort study. Ann Intern Med 170, 230-239.

29. Twig G, Tirosh A, Leiba A et al. (2016) BMI at age 17 years and diabetes mortality in midlife: a nationwide cohort of 2.3 million adolescents. Diabetes Care 39, 1996-2003.

30. Rosettie KL, Micha R, Cudhea F et al. (2018) Comparative risk assessment of school food environment policies and childhood diets, childhood obesity, and future cardiometabolic mortality in the United States. PLoS One 13, e0200378.

31. Carslake D, Jeffreys M \& Davey Smith G (2016) Being overweight in early adulthood is associated with increased mortality in middle age. Sci Rep 6, 36046.

32. Whitaker RC, Wright JA, Pepe MS et al. (1997) Predicting obesity in young adulthood from childhood and parental obesity. N Engl J Med 337, 869-873.

33. Geserick M, Vogel M, Gausche R et al. (2018) Acceleration of BMI in early childhood and risk of sustained obesity. NEnglJ Med 379, 1303-1312.

34. Singh AS, Mulder C, Twisk JW et al. (2008) Tracking of childhood overweight into adulthood: a systematic review of the literature. Obes Rev $9,474-488$.

35. DiCesare M, Sorić M, Bovet P et al. (2019) The epidemiological burden of obesity in childhood: a worldwide epidemic requiring urgent action. BMC Med 17, 212.

36. Reinehr $\mathrm{T}$ (2013) Lifestyle intervention in childhood obesity: changes and challenges. Nat Rev Endocrinol 9, 607-614.

37. WHO (2014) Comprehensive Implementation Plan on Maternal, Infant and Young Child Nutrition. https://www. who.int/nutrition/publications/CIP_document/en/ (accessed May 2020).

38. WHO (2015) Global Action Plan for the Prevention and Control of NCDs 2013-2020. http://www.who.int/nmh/ events/ncd_action_plan/en/ (accessed May 2020).

39. WHO (2018) Nutrition: Global Targets 2025. http:// www.who.int/nutrition/global-target-2025/en/ (accessed May 2020).

40. WHO (2016) Commission on Ending Childhood Obesity. Report of the Commission on Ending Childhood Obesity. Geneva: WHO. https://apps.who.int/iris/handle/10665/ 204176 (accessed May 2020).

41. Kelishadi R, Haghdoost AA, Sadeghirad B et al. (2014) Trend in the prevalence of obesity and overweight among Iranian children and adolescents: a systematic review and meta-analysis. Nutrition 30, 393-400.

42. Keane E, Kearney PM, Perry IJ et al. (2014) Trends and prevalence of overweight and obesity in primary school aged children in the Republic of Ireland from 2002-2012: a systematic review. BMC Public Health 14, 974.

43. Alper Z, Ercan İ \& Uncu Y (2018) A meta-analysis and an evaluation of trends in obesity prevalence among children and adolescents in Turkey: 1990 through 2015. J Clin Res Pediatr Endocrinol 10, 59-67.

44. Rahmani A, Sayehmiri K, Asadollahi K et al. (2015) Investigation of the prevalence of obesity in Iran: 
a systematic review and meta-analysis study. Acta Med Iran 53, 596-607.

45. Al-Quwaidhi AJ, Pearce MS, Critchley JA et al. (2014) Trends and future projections of the prevalence of adult obesity in Saudi Arabia, 1992-2022. East Mediterr Health J 20, 589-595.

46. GBD 2015 Eastern Mediterranean Region Obesity Collaborators (2018) Burden of obesity in the Eastern Mediterranean Region: findings from the Global Burden of Disease 2015 study. Int J Public Health 63, 165-176.

47. Hosseini M, Yousefifard M, Baikpour M et al. (2020) Age-period-cohort analysis of abdominal obesity in Iranian children and adolescents: the CASPIAN study. Int $J$ Endocrinol Metab 18, e82866.

48. NCD Risk Factor Collaboration (2017) Worldwide trends in body-mass index, underweight, overweight, and obesity from 1975 to 2016: a pooled analysis of 2416 populationbased measurement studies in 128.9 million children, adolescents, and adults. Lancet 390, 2627-2642.

49. Wabitsch M, Moss A \& Kromeyer-Hauschild K (2014) Unexpected plateauing of childhood obesity rates in developed countries. BMC Med 12, 17.

50. Ogden CL, Carroll MD, Lawman HG et al. (2016) Trends in obesity prevalence among children and adolescents in the United States, 1988-1994 through 2013-2014. JAMA 315 , 2292-2299.

51. Skinner AC \& Skelton JA (2014) Prevalence and trends in obesity and severe obesity among children in the United States, 1999-2012. JAMA Pediatr 168, 561-566.

52. Rodd C \& Sharma AK (2016) Recent trends in the prevalence of overweight and obesity among Canadian children. CMAJ 188, E313-E320.

53. Sánchez-Cruz JJ, de Ruiter I, Jiménez-Moleón JJ et al. (2018) Stabilization and reversal of child obesity in Andalusia using objective anthropometric measures by socioeconomic status. BMC Pediatr 18, 322.

54. Olds TS, Tomkinson GR, Ferrar KE et al. (2010) Trends in the prevalence of childhood overweight and obesity in Australia between 1985 and 2008. Int J Obes 34, 57-66.

55. Keß A, Spielau U, Beger C et al. (2017) Further stabilization and even decrease in the prevalence rates of overweight and obesity in German children and adolescents from 2005 to 2015: a cross-sectional and trend analysis. Public Health Nutr 20, 3075-3083.

56. Lioret S, Touvier M, Dubuisson C et al. (2009) Trends in child overweight rates and energy intake in France from 1999 to 2007: relationships with socioeconomic status. Obesity 17, 1092-1100

57. Péneau S, Salanave B, Maillard-Teyssier L et al. (2009) Prevalence of overweight in 6- to 15-year-old children in central/western France from 1996 to 2006: trends toward stabilization. Int J Obes 33, 401-407.

58. de Wilde JA, Verkerk PH \& Middelkoop BJ (2014) Declining and stabilising trends in prevalence of overweight and obesity in Dutch, Turkish, Moroccan and South Asian children 3-16 years of age between 1999 and 2011 in the Netherlands. Arch Dis Child 99, 46-51.

59. Herter-Aeberli I, Osuna E, Sarnovská Z et al. (2019) Significant decrease in childhood obesity and waist circumference over 15 years in Switzerland: a repeated cross-sectional study. Nutrients 11, 1922.

60. Bygdell M, Ohlsson C, Célind J et al. (2017) The rise and the recent decline of childhood obesity in Swedish boys: the BEST cohort. Int J Obes 41, 807-812.

61. Aboul-Enein BH, Bernstein J \& Neary AC (2017) Dietary transition and obesity in selected Arabic speaking countries: a review of the current evidence. East Mediterr Health J 22, $763-770$.

62. Elkum N, Al-Arouj M, Sharifi M et al. (2016) Prevalence of childhood obesity in the state of Kuwait. Pediatr Obes 11, e30-e34.
63. Al Hammadi H \& Reilly JJ (2020) Classification accuracy of body mass index for excessive body fatness in Kuwaiti adolescent girls and young adult women. Diabetes Metab Syndr Obes 13, 1043-1049.

64. de Onis M, Onyango AW, Borghi E et al. (2007) Development of a WHO growth reference for school-aged children and adolescents. Bull World Health Organ 85 , 660-667.

65. Ogden CL, Kuczmarski RJ, Flegal KM et al. (2002) Centers for disease control and prevention 2000 growth charts for the United States: improvements to the 1977 National Center for Health Statistics version. Pediatrics 109, 45-60.

66. Cole TJ, Bellizzi MC, Flegal KM et al. (2000) Establishing a standard definition for child overweight and obesity worldwide: international survey. BMJ 320, 1240-1243.

67. Cole TJ \& Lobstein T (2012) Extended international (IOTF) body mass index cut-offs for thinness, overweight and obesity. Pediatr Obes 7, 284-294.

68. UNISCO (2020) UNISCO Institute for Statistics/Education and Literacy 2020. http://uis.unesco.org/en/country/kw (accessed June 2020).

69. Al-Taiar A, Alqaoud N, Hammoud MS et al. (2020) WHO infant and young child feeding indicators in relation to anthropometric measurements. Public Health Nutr 23, $1665-1676$.

70. Ministry of Health (2015) Kuwait - Global School-Based Student Health Survey 2015. https://extranet.who.int/ ncdsmicrodata/index.php/catalog/545/study-description (accessed June 2020).

71. StataCorp. (2015) Stata Statistical Software. College Station, TX: StataCorp. LP.

72. Joinpoint Regression Program (2020) Version 4.8.0.1. Statistical Methodology and Applications Branch, Surveillance Research Program, National Cancer Institute. https://surveillance.cancer.gov/joinpoint/ (accessed June 2020).

73. Ingram D, Malec DJ, Makuc DM et al. (2018) National center for health statistics guidelines for analysis of trends. Vital Health Stat 2 (179), 1-71.

74. Lauria L, Spinelli A, Buoncristiano M et al. (2019) Decline of childhood overweight and obesity in Italy from 2008 to 2016: results from 5 rounds of the population-based surveillance system. BMC Public Health 19, 618.

75. OECD (2017) Obesity Update 2017. https://www.oecd.org/ els/health-systems/Obesity-Update-2017.pdf (accessed May 2020)

76. Horta BL, Loret de Mola C \& Victora CG (2015) Long-term consequences of breastfeeding on cholesterol, obesity, systolic blood pressure and type 2 diabetes: a systematic review and meta-analysis. Acta Paediatr 104, 30-37.

77. Hill JO (2006) Understanding and addressing the epidemic of obesity: an energy balance perspective. Endocr Rev 27, 750-761.

78. Hardcastle SJ, Thøgersen-Ntoumani C \& Chatzisarantis NL (2015) Food choice and nutrition: a social psychological perspective. Nutrients 7, 8712-8715.

79. Bancej C, Jayabalasingham B, Wall RW et al. (2015) Evidence brief - trends and projections of obesity among Canadians. Health Promot Chronic Dis Prev Can 35, 109-112.

80. Olds T, Maher C, Zumin S et al. (2011) Evidence that the prevalence of childhood overweight is plateauing: data from nine countries. Int J Pediatr Obes 6, 342-360.

81. van Jaarsveld CH \& Gulliford MC (2015) Childhood obesity trends from primary care electronic health records in England between 1994 and 2013: population-based cohort study. Arch Dis Child 100, 214-219.

82. Stamatakis E, Zaninotto P, Falaschetti E et al. (2010) Time trends in childhood and adolescent obesity in England from 1995 to 2007 and projections of prevalence to 2015. J Epidemiol Community Health 64, 167-174. 
83. Sjöberg A, Lissner L, Albertsson-Wikland K et al. (2008) Recent anthropometric trends among Swedish school children: evidence for decreasing prevalence of overweight in girls. Acta Paediatr 97, 118-123.

84. Wijnhoven TM, van Raaij JM, Spinelli A et al. (2014) WHO European childhood obesity surveillance initiative: body mass index and level of overweight among 6-9-year-old children from school year 2007-2008 to school year 2009-2010. BMC Public Health 14, 806.

85. Sweeting HN (2008) Gendered dimensions of obesity in childhood and adolescence. Nutr J 7, 1.

86. Simen-Kapeu A \& Veugelers PJ (2010) Should public health interventions aimed at reducing childhood overweight and obesity be gender-focused? BMC Public Health 10, 340.

87. Musaiger AO, Al-Mannai M \& Al-Marzog Q (2014) Overweight and obesity among children (10-13 years) in Bahrain: a comparison between two international standards. PakJ Med Sci 30, 497-500.
88. Vidal E, Carlin E, Driul D et al. (2006) A comparison study of the prevalence of overweight and obese Italian preschool children using different reference standards. Eur J Pediatr 165, 696-700

89. El-Ghaziri M, Boodai S, Young D et al. (2011) Impact of using national v. international definitions of underweight, overweight and obesity: an example from Kuwait. Public Health Nutr 14, 2074-2078.

90. Akinbami LJ \& Ogden CL (2009) Childhood overweight prevalence in the United States: the impact of parentreported height and weight. Obesity 17, 1574-1580.

91. He J, Cai Z \& Fan X (2018) How accurate is the prevalence of overweight and obesity in children and adolescents derived from self-reported data? A meta-analysis. Public Health Nutr 21, 1865-1873.

92. Wellens RI, Roche AF, Khamis HJ et al. (1996) Relationships between the body mass index and body composition. Obes Res 4, 35-44. 